\title{
Factors influencing citizen participation in community management
}

\author{
Ali Shamai ${ }^{a^{*}}$, Hamid Abya ${ }^{b^{*}}$ and Mohsen Ebrahimic \\ ${ }^{a}$ Associated professor, Department of Geography, University of Kharazmi, Tehran, Iran \\ ${ }^{b}$ Department of Geography, University of Kharazmi, Tehran, Iran \\ ${ }^{c}$ Department of Management, Tarbiat Modarres University, Tehran, Iran

\section{H R O N I C L E} \\ A B S T R A C T
}

\begin{tabular}{l}
\hline Article history: \\
Received October 28, 2014 \\
Received in revised format 15 \\
January 2015 \\
Accepted 28 January 2015 \\
Available online \\
February 12015 \\
\hline Keywords: \\
Tehran municipality \\
Citizen participation \\
Community management
\end{tabular}

\begin{abstract}
The primary objective of this study is to assess the factors affecting citizen participation in community management in district 13 of Tehran Municipality. Measured variables are: social cohesion, profitable partnerships, social-economic agencies, trust among civilians, trust in municipality management, feelings of powerlessness and social anomie. The results of the implementation of Pearson correlation test show that all of these variables had significant relationships with community participation in neighborhood management. The results of multiple regression analysis showed that three variables of social cohesion, profitable partnerships and socio-economic status had explained $37 \%$ of changes in citizen participation in community management while the changing social cohesion maintained the highest impact.
\end{abstract}

\section{Introduction}

Citizen participation builds good potentials for schools, neighborhoods, and other institutions, environments, and services responsive for sharing appropriate experiences (Plummer, 1999; Wandersman \& Florin, 2000). According to Hart (2013), young citizens play essential role for building a good community. Schelp (1988) also emphasized on the role of organizations in community participation-prevention of accidental injuries in a rural Swedish municipality. Fiorino (1990) presented a survey of five institutional mechanisms for permitting the lay public to impact on environmental risk decisions including public hearings, initiatives, public surveys, negotiated rule making, and citizens review panels. They defined democratic process criteria for evaluating these and other participatory mechanisms. Lestari et al. (2015) investigated voluntary participation in community forest management, and specified how more participation could be induced. They used a survey of 571 respondents and performed a case study in Central Java, Indonesia. They reported that voluntary participation could respond to key determinants, such as education and income, in various directions,

\footnotetext{
*Corresponding author.

E-mail addresses: ShamaiAli@yahoo.com (T. Faraji) 
according to each of the three levels. Nevertheless, the publicly organized programs, such as information provision of benefit sharing, were effective, irrespective of the levels of participation. In summary, the results recommended a possibility of further success and corrective measures to enhance the participation in community forest management. According to Arai and Pedlar (1997), building communities through leisure could lead to citizen participation in a healthy community initiative.

According to Druetz et al. (2015), the use of community health workers to administer prompt treatments is becoming popular in many African countries. Their performance is the primary key challenge because it differs, significantly, depending on the context. Druetz et al. (2015) performed an investigation in Burkina Faso, where health authorities applied a national program introducing community case management of malaria. The primary objective was to evaluate the presence of the mechanisms in community health workers, and investigate the effect of contextual factors. In 2012, they performed semi-structured interviews with 35 community health workers from a study area accomplished in two similar health districts. They reported that they perceive most of the mechanisms, except the sense of being valued by the health system and accountability to village members. Their survey also showed that drug stock-outs and past experiences of community health workers impacted the presence of several mechanisms, simultaneously.

Akamani and Hall (2015) examined a proposed community resilience technique by studying the role of institutions, capital assets, community and socio-demographic variables as determinants of households' participation in Ghana's collaborative forest management (CFM) program and outcomes of the program. They reported that households' participation in the CFM program could be forecasted by community location, past connections with institutions, and past bonding social capital. Community location and past capitals were the biggest predictors of the outcomes of the CFM program as judged by current levels of capitals. In their survey, participation in the CFM program also maintained a positive impact on human capital but had minimal effect on the other capitals impacting household well-being and resilience, recommending that the effect of co-management on household resilience could be modest. In all, their results shed light on the need for co-management policies to focus on the historical context of community interaction processes impacting access to capital assets and local institutions to successfully promote equitable resilience.

Mongkolnchaiarunya (2005) described a successful case of community cooperation by encouraging replacement of egg by garbage. In this study, residents were encouraged to bring recyclable stuff to exchange for eggs, at monthly exchanges in local communities. The project focused not only at garbage reduction, but also at community empowerment through self-reliance, establishing new relationships of equality and less dependence, between poor communities and the municipal administration. The project appeared to be succeeded in promoting clearance of a backlog of discarded items such as glass, improving the environment of the communities; but the quantities brought for exchange then reduced steadily over a year of monitoring.

\section{The proposed study}

The primary objective of this study is to assess the factors affecting citizen participation in community management in district 13 of Tehran Municipality. Measured variables are: social cohesion, profitable partnerships, social-economic agencies, interpersonal trust, trust in municipality management, feelings powerlessness and social anomie. The proposed study considers the following six hypotheses,

1. There is a significant relationship between socio-economic agencies and citizen participation in the management of district 13 of city of Tehran (Choguill, 1996).

2. There is a significant relationship between trust among civilians and citizen participation in the management of district 13 of city of Tehran (Davidson et al., 2007). 
3. There is a significant relationship between trust to municipality and citizen participation in the management of district 13 of city of Tehran (Davidson et al., 2007).

4. There is a significant relationship between social cohesion and citizen participation in the management of district 13 of city of Tehran (Joseph, 2006).

5. There is a significant relationship between feelings powerlessness and citizen participation in the management of district 13 of city of Tehran (Joseph, 2006).

6. There is a significant relationship between social anomie and citizen participation in the management of district 13 of city of Tehran (Folz, 1991).

The population of the survey includes all residences who live in district 13 of city of Tehran, Iran. The sample size is calculated as follows,

$$
N=Z_{\alpha / 2}^{2} \frac{p \times q}{e^{2}},
$$

where $N$ is the sample size, $p=1-q$ represents the probability, $z_{\alpha / 2}$ is CDF of normal distribution and finally $\varepsilon$ is the error term. For our study we assume $p=0.5, z_{\alpha / 2}=1.96$ and $e=0.05$, the number of sample size is calculated as $N=384$. In this study, we have distributed 387 questionnaires among residences. Table 1 demonstrates Cronbach alphas for different components of the survey.

\section{Table 1}

The summary of Cronbach alphas

\begin{tabular}{lcc}
\hline Variable & Number of questions & Cronbach alpha \\
\hline Trust among civilians & 6 & 0.80 \\
Trust to municipality management & 6 & 0.89 \\
Social cohesion & 7 & 0.89 \\
Profitable participation & 4 & 0.68 \\
Feelings powerlessness & 6 & 0.77 \\
Social anomie & 6 & 0.84 \\
Citizen participation & 10 & 0.74 \\
\hline
\end{tabular}

As we can observe from the results of Table 1, all components of the survey have maintained desirable values, which confirms the overall questionnaire. Fig. 1 demonstrates the results of personal characteristics of the participants.

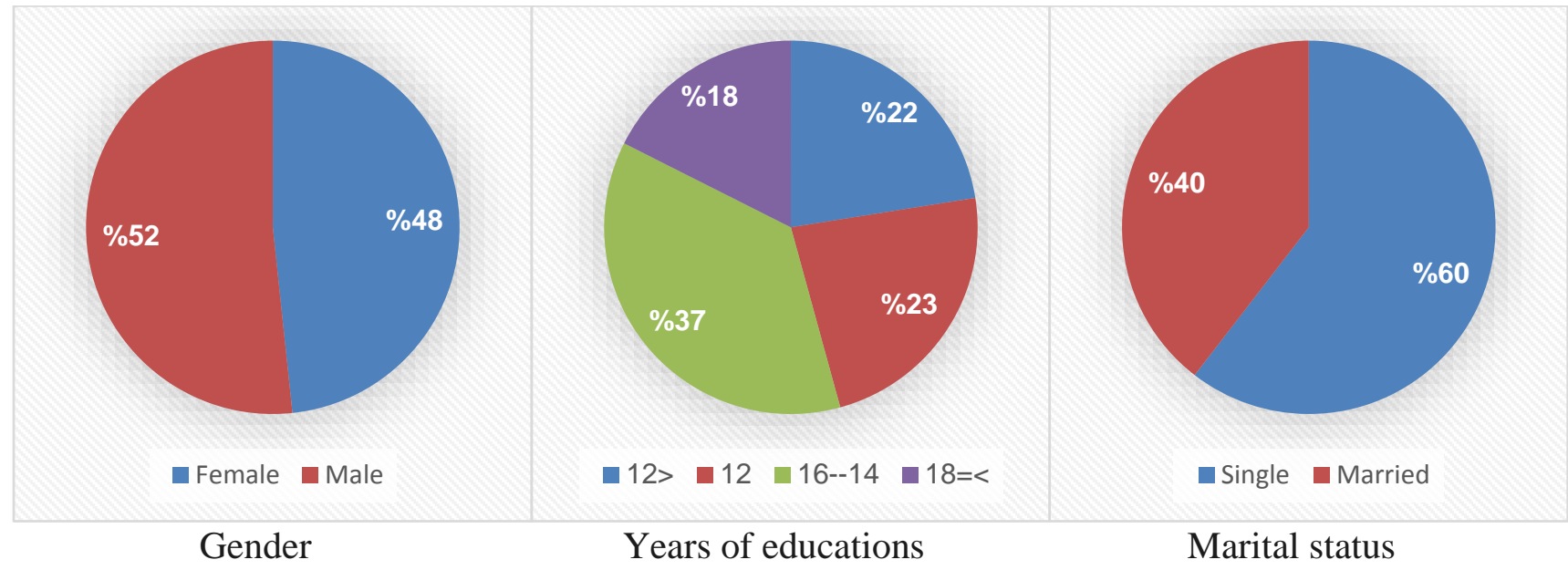

Fig. 1. Personal characteristics of the participants 
In our survey, 269 surveyed people lived in their own house and 81 ones rented the house. In addition, 160 people were employed, 68 people were student, 87 were housekeeper, 21 were unemployed, 12 were attending military service and 34 people were retired. Table 2 shows the summary of some basic statistics.

\section{Table 2}

The summary of some basic statistics

\begin{tabular}{lccc}
\hline Variable & Range & Mean & Standard deviation \\
\hline Trust among civilians & $1-5$ & 3.18 & 0.52 \\
Trust to municipality management & $1-5$ & 2.60 & 0.86 \\
Social cohesion & $1-5$ & 2.98 & 0.79 \\
Profitable participation & $1-4$ & 3.08 & 0.47 \\
Feelings powerlessness & $1-4$ & 2.78 & 0.58 \\
Social anomie & $1-4$ & 2.83 & 0.66 \\
Citizen participation & 1.2 & 1.41 & 0.21 \\
\hline
\end{tabular}

In order to verify the hypotheses of the survey, we have to first make sure the data were normally distributed. This has confirmed through Kolmogorov-Smirnov test and according to our survey the data were normally distributed when the level of significance is one percent.

\section{The results}

In this section, we present details of our findings on testing various hypotheses of the survey. Table 3 demonstrates the results of Pearson correlation.

\section{Table 3}

The summary of Pearson correlation between indpendent variables of the survey and citizen participation in community management

\begin{tabular}{lcc}
\hline Variable & Correlation & Sig. \\
\hline Trust among civilians & 0.261 & 0.000 \\
Trust to municipality management & 0.328 & 0.000 \\
Social cohesion & 0.561 & 0.000 \\
Profitable participation & 0.394 & 0.000 \\
Socio-economic participation & 0.285 & 0.000 \\
Feelings powerlessness & -0.422 & 0.000 \\
Social anomie & -0.333 & 0.000 \\
\hline
\end{tabular}

As we can observe from the results of Table 3, there are positive correlations between citizen participation in community management and five components of the survey including Trust among civilians, Trust to municipality management, Social cohesion, Profitable participation and Socioeconomic participation on the other side. Next, we present the results of stepwise regression technique where dependent variable is citizenship participation in community management and other mentioned variables are independent variables. Table 4 shows details of our survey.

\section{Table 4}

The summary of stepwise regression technique

\begin{tabular}{lcccc}
\hline Variable & Non-Standard $\beta$ & Standard deviation & Standard $\beta$ & Sig. \\
\hline Intercept & 2.248 & 0.071 & & 0.000 \\
Social cohesion & -0.096 & 0.017 & 0.345 & 0.000 \\
Profitable participation & -0.088 & 0.029 & 0.189 & 0.002 \\
Socio-economic participation & 0.140 & 0.033 & 0.174 & 0.009 \\
\hline
\end{tabular}

R-Square $=0.37$ 
As we can observe from the results of Table 4, social cohesion maintains the highest impact followed by profitable participation and socio-economic participation.

\section{Conclusion}

In this paper, we have presented an empirical investigation to study the effects of different factors on citizen participation in community management in one of regional manicipalities of city of Tehran, Iran. Using Pearson correlation test as well as stepwise regression technique, the study has determined that social cohesion has maintained the highest positive impact on citizen participation in community management. In addition, when the residence felt the participation could virtually benefit community, they tended more to join the community for social cooperations. In our survey, if citizens are more familiar with the neighborhood and management activities and the benefits of their participation in the community, they will be more engaged in community management. The results of this study are consistent with findings of Mongkolnchaiarunya (2005). The management may use different tools such as newspapers, radio and television, etc. to introduce social programs for citizens and encourage them to participate in programs.

\section{Acknowledgement}

The authors would like to thank the anonymous referees for constructive comments on earlier version of this paper.

\section{References}

Akamani, K., \& Hall, T. E. (2015). Determinants of the process and outcomes of household participation in collaborative forest management in Ghana: A quantitative test of a community resilience model. Journal of Environmental Management, 147, 1-11.

Arai, S. M., \& Pedlar, A. M. (1997). Building communities through leisure: Citizen participation in a healthy communities initiative. Journal of Leisure Research, 29, 167-182.

Choguill, M. B. G. (1996). A ladder of community participation for underdeveloped countries. Habitat international, 20(3), 431-444.

Davidson, C. H., Johnson, C., Lizarralde, G., Dikmen, N., \& Sliwinski, A. (2007). Truths and myths about community participation in post-disaster housing projects. Habitat International, 31(1), 100115.

Druetz, T., Kadio, K., Haddad, S., Kouanda, S., \& Ridde, V. (2015). Do community health workers perceive mechanisms associated with the success of community case management of malaria? A qualitative study from Burkina Faso. Social Science \& Medicine, 124, 232-240.

Fiorino, D. J. (1990). Citizen participation and environmental risk: A survey of institutional mechanisms. Science, Technology \& Human Values, 15(2), 226-243.

Folz, D. H. (1991). Recycling program design, management, and participation: a national survey of municipal experience. Public Administration Review, 51(3), 222-231.

Hart, R. A. (2013). Children's participation: The theory and practice of involving young citizens in community development and environmental care. Routledge.

Joseph, K. (2006). Stakeholder participation for sustainable waste management. Habitat International, 30(4), 863-871.

Lestari, S., Kotani, K., \& Kakinaka, M. (2015). Enhancing voluntary participation in community collaborative forest management: A case of Central Java, Indonesia. Journal of Environmental Management, 150, 299-309.

Mongkolnchaiarunya, J. (2005). Promoting a community-based solid-waste management initiative in local government: Yala municipality, Thailand. Habitat International, 29(1), 27-40.

Plummer, J. (1999). Municipalities and community participation: a sourcebook for capacity building. Earthscan. 
Schelp, L. (1988). The role of organizations in community participation-prevention of accidental injuries in a rural Swedish municipality. Social Science \& Medicine, 26(11), 1087-1093.

Wandersman, A., \& Florin, P. (2000). Citizen participation and community organizations. In Handbook of community psychology (pp. 247-272). Springer US. 